\title{
IL-22 alleviates the fibrosis of hepatic stellate cells via the inactivation of NLRP3 inflammasome signaling
}

\author{
ZHUYUN XING ${ }^{1}$, YAYUN WU ${ }^{1}$ and NA LIU ${ }^{2}$ \\ ${ }^{1}$ Department of Infectious Diseases, Affiliated Hospital of Guizhou Medical University, \\ Guiyang, Guizhou 550004; ${ }^{2}$ Department of Hepatology, The Second Hospital of Nanjing, \\ Nanjing University of Chinese Medicine, Nanjing, Jiangsu 210000, P.R. China
}

Received October 13, 2020; Accepted February 12, 2021

DOI: $10.3892 /$ etm.2021.10522

\begin{abstract}
Persistent and progressive liver injury causes liver fibrosis due to the inability of the liver to regenerate. Interleukin (IL)-22 serves an important role in liver fibrosis. However, the underlying mechanism by which IL-22 exerts its effects on liver fibrosis has not been fully elucidated. The aim of the present study was to investigate the underlying mechanism by which IL-22 affects the development of liver fibrosis. Following activation of the hepatic stellate cells (HSCs) using transforming growth factor $\beta$ (TGF- $\beta$ ), HSC proliferation was measured using the Cell Counting Kit- 8 assay. The indicators of oxidative stress were detected using specific kits. In addition, the mRNA and protein expression levels of fibrosis-associated genes were determined using reverse transcription-quantitative polymerase chain reaction and western blot analysis, respectively. Subsequently, the protein expression levels of the NOD-like receptor protein 3 (NLRP3), caspase-1 and IL-1 $\beta$ were examined using western blotting. Following addition of Nigericin, a NLRP3 activator, the levels of oxidative stress and fibrosis were measured. IL-22 increased the viability of HSCs, which were activated by TGF- $\beta$. The malondialdehyde content was significantly decreased, whereas superoxide dismutase and glutathione levels were increased following IL-22 treatment. Moreover, IL-22 markedly downregulated the expression levels of fibrosis-associated genes, including $\alpha$-smooth muscle actin, type I collagen and TIMP metallopeptidase inhibitor 1. Furthermore, the expression levels of NLRP3, caspase-1 and IL-1 $\beta$ were decreased in the IL-22-treated groups. However, the NLRP3 activator Nigericin reversed the inhibitory effects of IL-22 on the induction of oxidative stress and fibrosis of HSCs induced by TGF- $\beta$. In conclusion, the present study indicated that IL-22 alleviated the fibrosis of HSCs by inactivation
\end{abstract}

Correspondence to: Dr Na Liu, Department of Hepatology, The Second Hospital of Nanjing, Nanjing University of Chinese Medicine, 1-1 Zhongfu Road, Nanjing, Jiangsu 210000, P.R. China E-mail: liunannn0@163.com

Key words: liver fibrosis, hepatic stellate cells, NOD-like receptor protein 3 inflammasome, oxidative stress, interleukin-22 of NLRP3 inflammasome signaling, which may provide further insight on the underlying mechanism by which IL-22 exerts protective effects on liver fibrosis.

\section{Introduction}

Persistent and progressive liver injury results in the inability of the liver to regenerate and leads to liver fibrosis (1). Liver fibrosis is a wound healing response that is closely associated with hepatic stellate cells (HSCs) and Kupffer cells (2). The activation and accumulation of a large number of HSCs is a pivotal step in the formation and progression of liver fibrosis (3). Initiation and perpetuation are two stages that constitute the activation of HSCs (4). Persistent activation of HSCs can contribute to cellular events, including extracellular matrix degradation and cytokine release, which result in the production and accumulation of fibrotic extracellular matrix components, including $\alpha$-smooth muscle actin ( $\alpha$-SMA) and collagen type I $\alpha 1$ (COL1A1) (5). Additionally, HSCs can synthesize and secrete TIMP metallopeptidase inhibitor 1 (TIMP1), which is a powerful inhibitor of enzymes that degrade matrix molecules and serves a critical role in fibrosis (6). Overall, liver fibrosis has become an obstacle in clinical trials or during treatment of patients with chronic liver diseases (7). Therefore, there is an urgent need to identify novel and effective treatment strategies for this disease.

Interleukin (IL)-22 was originally identified as an IL-10-related T cell-derived inducible factor (8). IL-22 is an actively secreted protein of 146 amino acids, which belongs to the IL-10 family of cytokines $(9,10)$. Despite the differences noted in primary sequences among IL-10 members, they share a common gene structure containing six helices (11). IL-22 expression is downregulated in the serum of mice and in diabetic nephropathy patients (12). By binding to the IL-22 receptor subunit $\alpha-1$ (IL-22RA1) and IL-10R2, IL-22 exerts protective effects on hepatocytes (13). It has been shown that the binding of IL-22 to IL-22RA1 can induce senescence of HSCs and ameliorate liver fibrosis (14). However, the activation of several signaling pathways, such as STAT3, SOCS3, p53 and Notch, induced by IL-22 inhibits the progression of liver damage (15).

Oxidative stress serves a crucial role in inducing HSC activation and fibrogenic potential (16). Superoxide dismutase 
(SOD), one of the most important protective enzymes, provides the first antioxidant defense system in various organs and tissues, including the liver (17). Glutathione (GSH) is a key reactive oxygen species scavenger to protect liver cells from oxidative stress (18). SOD and GSH serve an important role in the antioxidant defense system, while malondialdehyde (MDA) is considered to be the main marker of lipid peroxidation in tissues (19). Inflammation serves a critical role in the progression of liver injury and fibrosis. NOD-like receptor protein 3 (NLRP3) is a well-established inflammasome that consists of apoptosis-associated speck-like protein and the effector molecule pro-caspase-1 (20). Recent studies have confirmed the role of NLRP3 in a variety of liver diseases, such as alcoholic and non-alcoholic fatty liver diseases and non-alcoholic steatohepatitis $(21,22)$. Inhibition of the NLRP3 inflammasome can alleviate renal injury and fibrosis (23). NLRP3 is aberrantly activated in vivo and in vitro following exposure to aristolochic acid, and inhibition of NLRP3 ameliorates renal fibrosis and renal failure (24). However, whether IL-22 ameliorates liver fibrosis by directly inhibiting the activation of NLRP3 has not been previously investigated.

In the present study, the role of IL-22 was investigated in transforming growth factor $\beta$ (TGF- $\beta$ )-induced HSCs. Whether IL-22 exerted its effects on liver fibrosis via the regulation of NLRP3 inflammasome signaling was also explored. The current study may guide the future exploration of the pathogenesis of liver fibrosis.

\section{Materials and methods}

Cell culture and treatment. HSCs were purchased from the American Type Culture Collection and Nigericin (cat. no. N7143) was purchased from Sigma-Aldrich (Merck KGaA). HSCs were cultured in DMEM supplemented with $10 \%$ FBS (both Gibco; Thermo Fisher Scientific, Inc.), $100 \mathrm{U} / \mathrm{ml}$ penicillin and $100 \mathrm{mg} / \mathrm{ml}$ streptomycin in a PBS buffer (R\&D Systems, Inc.) at $37^{\circ} \mathrm{C}$ in an incubator with $95 \%$ air $/ 5 \% \mathrm{CO}_{2}$. The cells were treated with $5 \mathrm{ng} / \mathrm{ml}$ TGF- $\beta$ (Sigma-Aldrich; Merck $\mathrm{KGaA}$ ) at $37^{\circ} \mathrm{C}$ for $24 \mathrm{~h}$ and subsequently cultured in the presence of $250,500,750$ and $1,000 \mathrm{pg} / \mathrm{ml} \mathrm{IL-22}$ (Sigma-Aldrich; Merck KGaA) for $48 \mathrm{~h}$ at $37^{\circ} \mathrm{C}(25,26)$. Finally, the cells were treated with Nigericin $(40 \mu \mathrm{M})$ for $30 \mathrm{~min}$ at $37^{\circ} \mathrm{C}$ to activate NLRP3 for subsequent experiments (27).

Cell Counting Kit-8 (CCK-8) assay. The CCK-8 assay was conducted for the determination of cell viability. Briefly, HSCs $\left(3 \times 10^{4}\right.$ cells/well) were inoculated into a 96 -well plate at $37^{\circ} \mathrm{C}$. At $48 \mathrm{~h}$ after IL-22 treatment, $10 \mu \mathrm{l}$ CCK-8 reagent (Dojindo Molecular Technologies, Inc.) was added to each well and incubated for $3 \mathrm{~h}$. The absorbance at $450 \mathrm{~nm}$ was read using a microplate reader (Bio-Rad Laboratories, Inc.). Three replicates were conducted for each sample.

Apoptosis assay. Apoptosis was evaluated via flow cytometry. HSCs were collected and then re-suspended in $1 \mathrm{X}$ binding buffer to a concentration of $1 \times 10^{4}$ cells/well. An Annexin V-FITC Staining Cell Apoptosis Detection kit (Nanjing KeyGen Biotech Co., Ltd.) was employed to determine apoptosis in accordance with the manufacturer's protocol. Briefly, cells were stained with Annexin V-FITC and
PI, and incubated in the dark for $15 \mathrm{~min}$ at $37^{\circ} \mathrm{C}$. Cell apoptosis of each sample was assessed by flow cytometry (BD Accuri ${ }^{\mathrm{TM}}$ C6; BD Biosciences). Apoptosis was analyzed using FlowJo software (version 7.6.3; FlowJo LLC).

Detection of oxidative stress. The contents of MDA and GSH, as well as the activity of SOD, were respectively detected using the MDA assay kit (cat. no. A003-4-1), GSH assay kit (cat. no. A006-2-1) and SOD assay kit (cat. no. A001-3-2; all from Nanjing Jiancheng Bioengineering Institute) in accordance with the manufacturer's instructions.

Reverse transcription-quantitative polymerase chain reaction $(R T-q P C R)$. Total RNA was isolated from cells using TRIzol ${ }^{\circledR}$ reagent (Sigma-Aldrich; Merck KGaA). cDNA was synthesized using a Sensiscript RT kit (Qiagen $\mathrm{GmbH}$ ) following manufacturer's recommendations. According to the manufacturer's recommendations, PCR assays were conducted using SYBR-Green ${ }^{\circledR}$ Realtime PCR Master Mix and Premix Ex Taq (Takara Bio., Inc.) on ViiA ${ }^{\mathrm{TM}} 7$ Real-Time PCR System (Applied Biosystems; Thermo Fisher Scientific, Inc.). The following thermocycling conditions were used: $5 \mathrm{~min}$ at $95^{\circ} \mathrm{C}$, followed by 35 cycles at $95^{\circ} \mathrm{C}$ for $15 \mathrm{sec}, 40 \mathrm{sec}$ at $55^{\circ} \mathrm{C}$ and $72^{\circ} \mathrm{C}$ for $1 \mathrm{~min}$. Relative quantification of gene expression was performed using the $2^{-\Delta \Delta \mathrm{Cq}}$ method (28). The relative gene expression levels were normalized to those of GAPDH. Three independent experiments were conducted for each target gene. The sequences of the gene-specific primers used in the present study were as follows: $\alpha$-SMA forward, 5'-TCCAGAGTC CAGCACAATACCAG-3' and reverse, 5'-AATGACCCAGAT TATGTTTGAGACC-3'; COL1A1 forward, 5'-TCAGGGGCG AAGGCAACAGT-3' and reverse, 5'-TTGGGATGGAGG GAGTTTACACGA-3'; TIMP1 forward, 5'-ACCACCTTA TACCAGCGTTATGA-3' and reverse, 5'-GGTGTAGACGAA CCGGATGTC-3'; GAPDH forward, 5'-CTCACCGGATGC ACCAATGTT-3' and reverse, 5'-CGCGTTGCTCACAAT GTTCAT-3'.

Western blot analysis. HSCs were lysed in radioimmunoprecipitation (RIPA) lysis buffer (Beyotime Institute of Biotechnology) and the concentrations of the proteins were measured using a BCA protein assay (Shanghai Yeasen Biotechnology Co., Ltd.). Proteins (40 $\mu \mathrm{g} /$ lane) were separated via $10 \%$ SDS-PAGE and were transferred to PVDF membranes, which were then blocked with 5\% skimmed milk for $1 \mathrm{~h}$ at room temperature. Subsequently, the membranes were incubated at $4^{\circ} \mathrm{C}$ overnight with primary antibodies (all 1:1,000) against NLRP3 (cat. no. 15101S), IL-1 $\beta$ (cat. no. $12703 \mathrm{~S}$ ), caspase-1 (cat. no. 3866T), $\alpha$-SMA (cat. no. 19245T), COL1A1 (cat. no. 72026T), TIMP1 (cat. no. 8946S) and GAPDH (cat. no. 5174T; all from Cell Signaling Technology, Inc.). The membranes were washed three times with TBS-0.2\% Tween 20 before incubation with goat anti-rabbit HRP-conjugated secondary antibody (1:3,000; cat. no. 7074S; Cell Signaling Technology, Inc.) for $1 \mathrm{~h}$ at room temperature. The expression levels of the targeted proteins were determined using a Bio-Rad ChemiDoc MP imaging system (Bio-Rad Laboratories, Inc.). The bands were detected using an enhanced chemiluminescence reagent (EMD Millipore). The grayscale values of the membranes 

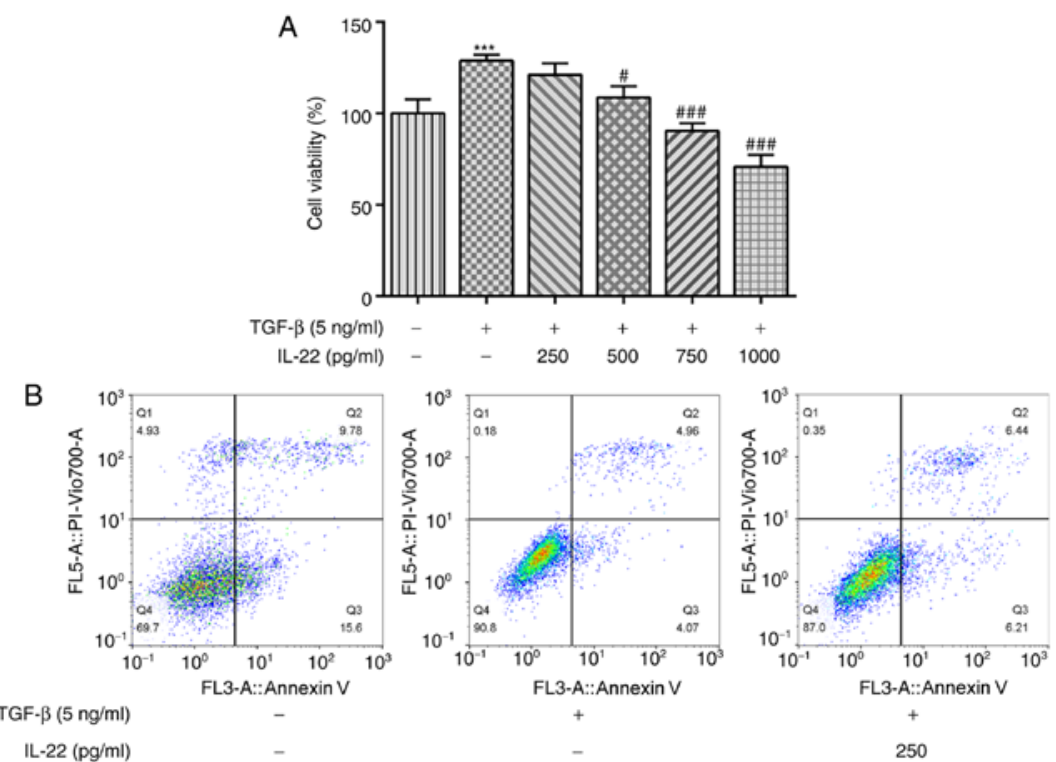

TGF- $\beta(5 \mathrm{ng} / \mathrm{ml})$
$\mathrm{IL}-22(\mathrm{pg} / \mathrm{ml})$

$+$
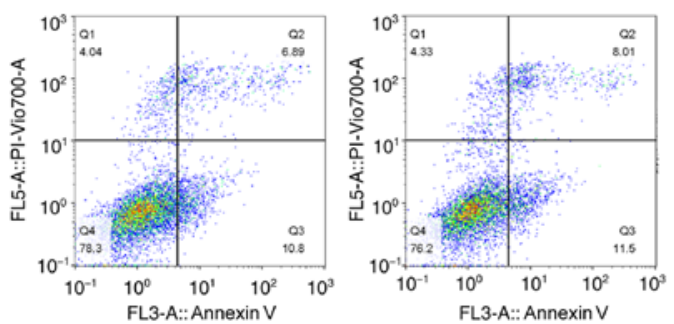

FL3-A:: Annexin V

$+$

750

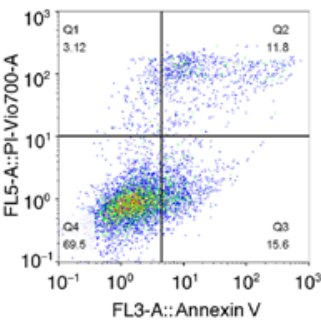

$+$

IL-22 (pg/ml) $\quad 500$

$\mathrm{D}$

1000
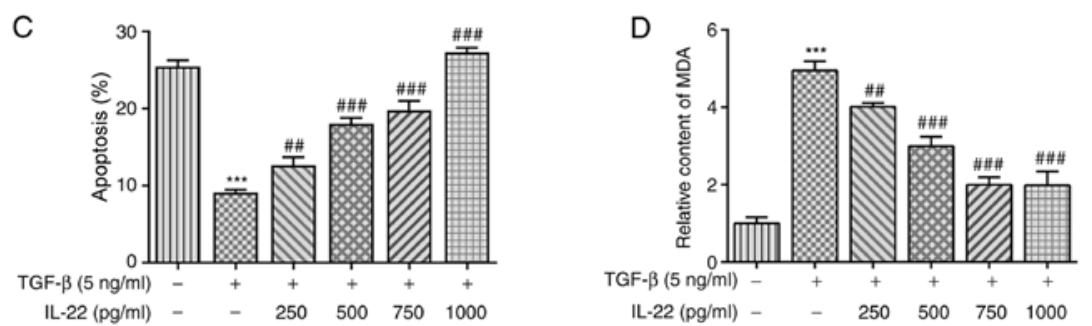

E
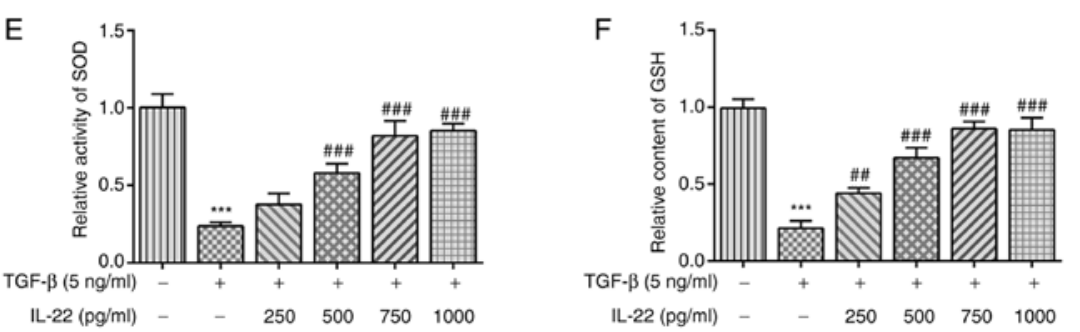

Figure 1. IL-22 attenuates viability and oxidative stress of HSCs activated by TGF- $\beta$. (A) Cell viability of HSCs was detected using the Cell Counting Kit-8 assay. (B and C) Flow cytometry analysis was used to detect the apoptotic rate of HSCs. The relative levels of (D) MDA, (E) SOD and (F) GSH in TGF- $\beta$-induced HSCs were detected using the corresponding commercial kits. ${ }^{* * *} \mathrm{P}<0.001$ vs. control. ${ }^{\#} \mathrm{P}<0.05$, ${ }^{\# \#} \mathrm{P}<0.01$ and ${ }^{\# \# \#} \mathrm{P}<0.001$ vs. TGF- $\beta$. IL-22, interleukin-22; HSCs, hepatic stellate cells; TGF- $\beta$, transforming growth factor $\beta$; MDA, malondialdehyde; SOD, superoxide dismutase; GSH, glutathione.

were semi-quantified using ImageJ software (version $1.52 \mathrm{r}$; National Institutes of Health). GAPDH was used as an internal control.

Statistical analysis. Data were analyzed using GraphPad Prism version 6.0 (GraphPad Software, Inc.). Data were expressed as the mean \pm SD. All experiments were performed three times. Comparisons between two groups were conducted by unpaired Student's t-test, while comparisons among multiple groups were performed by one-way ANOVA followed by Turkey's post-hoc test. $\mathrm{P}<0.05$ was considered to indicate a statistically significant difference.

\section{Results}

IL-22 attenuates HSC viability and oxidative stress activated by $T G F-\beta$. Following incubation of HSCs with TGF- $\beta$, their viability was significantly increased, while 

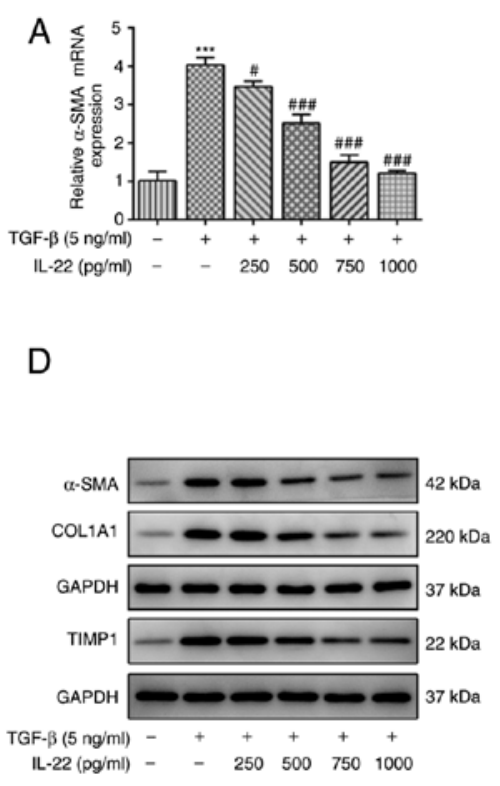
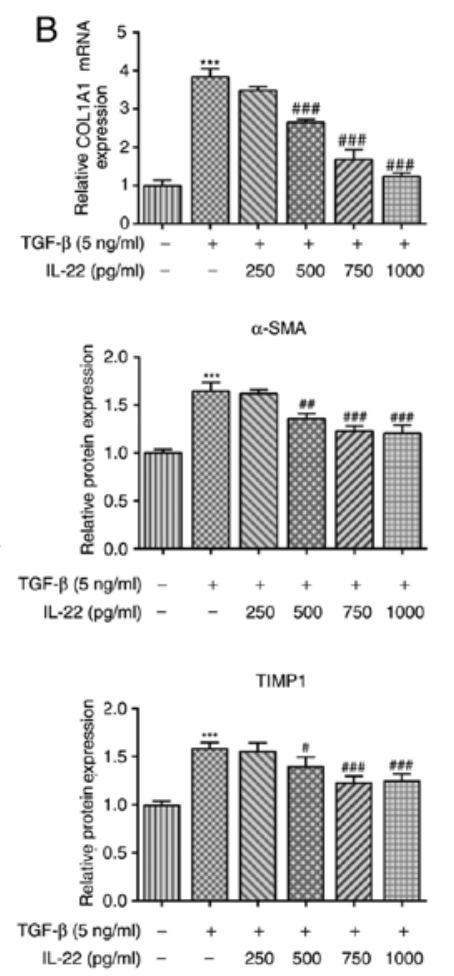
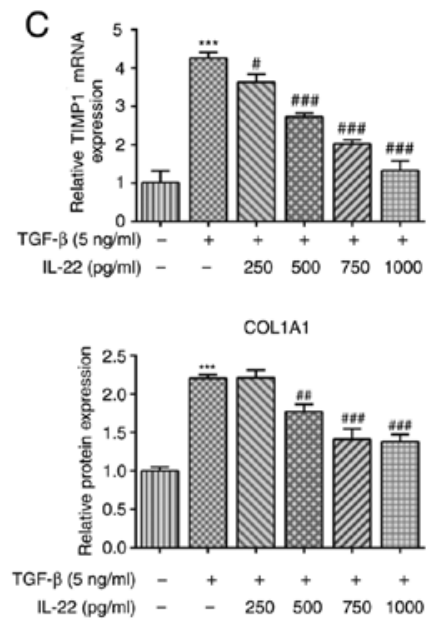

Figure 2. IL-22 inhibits HSC fibrosis activated by TGF- $\beta$. The mRNA expression levels of (A) $\alpha$-SMA, (B) COL1A1 and (C) TIMP1 in TGF- $\beta$-induced HSCs were detected by reverse transcription-quantitative polymerase chain reaction. (D) Protein expression levels of $\alpha$-SMA, COL1A1 and TIMP1 were measured via western blot analysis. ${ }^{* * *} \mathrm{P}<0.001$ vs. control. ${ }^{\#} \mathrm{P}<0.05,{ }^{\# \#} \mathrm{P}<0.01$ and ${ }^{\# \# \#} \mathrm{P}<0.001$ vs. TGF- $\beta$. IL-22, interleukin-22; HSCs, hepatic stellate cells; TGF- $\beta$, transforming growth factor $\beta$; $\alpha$-SMA, $\alpha$-smooth muscle actin; COL1A1, collagen type I $\alpha 1$; TIMP1, TIMP metallopeptidase inhibitor 1 .

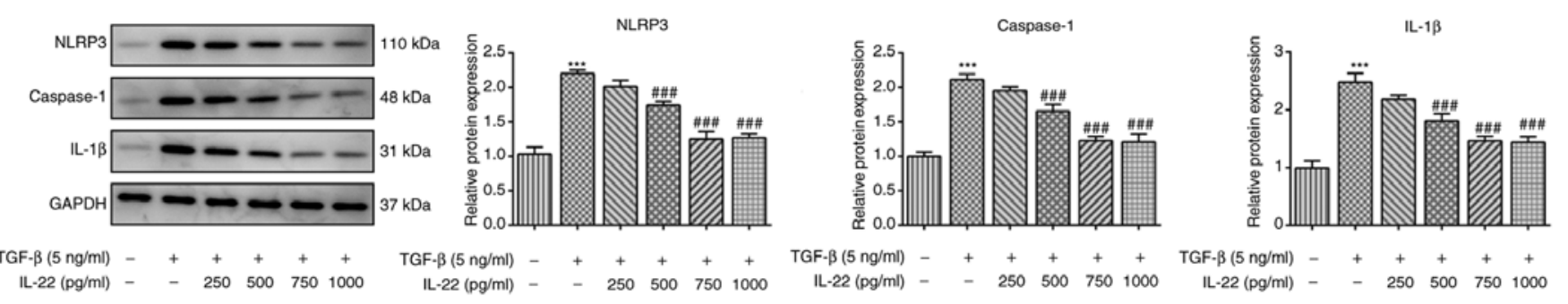

Figure 3. IL-22 inhibits NLRP3 inflammasome signaling in TGF- $\beta$-induced HSCs. Protein expression levels of NLRP3, caspase-1 and IL-1 $\beta$ in TGF- $\beta$-induced HSCs were measured by western blot analysis. ${ }^{* * *} \mathrm{P}<0.001$ vs. control. ${ }^{\# \#} \mathrm{P}<0.001$ vs. TGF- $\beta$. IL, interleukin; NLRP3, NOD-like receptor protein 3; TGF- $\beta$, transforming growth factor $\beta$; HSCs, hepatic stellate cells.

concomitant IL-22 treatment led to significant decreases in HSC viability in a dose-dependent manner (Fig. 1A). As shown in Fig. $1 \mathrm{~B}$ and $\mathrm{C}$, TGF- $\beta$ treatment significantly inhibited the apoptosis of HSCs compared with the untreated group. By contrast, IL-22 significantly increased TGF- $\beta$-induced apoptosis in a dose-dependent manner (Fig. 1B and C). Subsequently, factors associated with oxidative stress were measured using commercially available kits. As shown in Fig. 1D, TGF- $\beta$ stimulation caused a significant increase in the relative content of MDA, whereas increasing concentrations of IL-22 led to a gradual decrease in MDA levels. Conversely, the levels of SOD and GSH were significantly inhibited following TGF- $\beta$ treatment, whereas IL-22 restored their levels in a dose-dependent manner (Fig. 1E and F). Overall, these findings revealed that IL-22 inhibited viability and oxidative stress in HSCs induced by TGF- $\beta$.
IL-22 alleviates fibrosis of HSCs activated by TGF- $\beta$. Subsequently, the ability of IL-22 to inhibit HSC fibrosis activated by TGF- $\beta$ was assessed. To confirm this hypothesis, RT-qPCR and western blot analyses were conducted to assess the expression levels of fibrosis-associated genes. TGF- $\beta$ activation in HSCs significantly enhanced the mRNA and protein expression levels of $\alpha$-SMA, COL1A1 and TIMP1 compared with the levels in untreated HSCs (Fig. 2A-D). In addition, IL-22 treatment of HSCs activated by TGF- $\beta$ caused a downregulation in the expression levels of the aforementioned fibrosis-associated factors (Fig. 2A-D). Therefore, the results indicated that IL-22 suppressed HSC fibrosis activated by TGF- $\beta$.

IL-22 inhibits NLRP3 inflammasome signaling in TGF- $\beta$-induced HSCs. Subsequently, the expression levels of key proteins involved in the NLRP3 inflammasome signaling pathway were detected by 

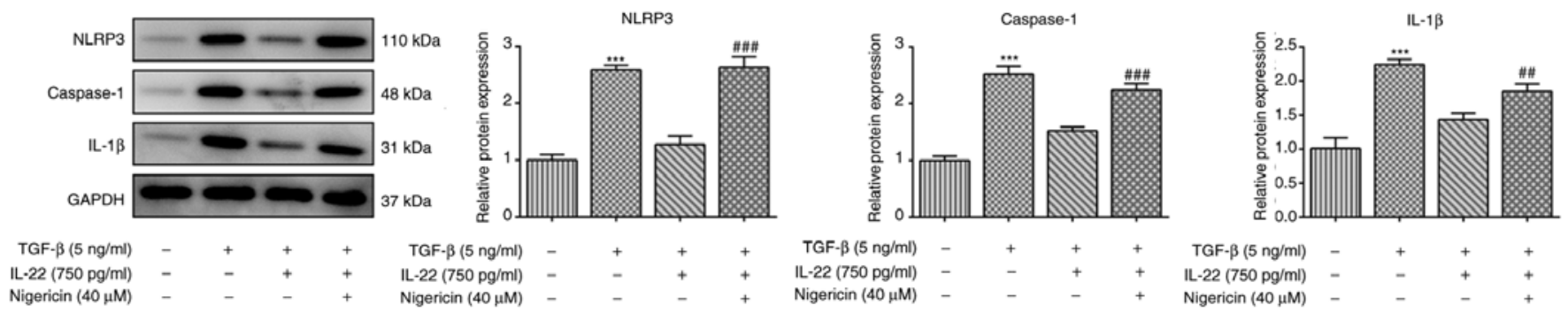

$\mathrm{IL}-22(750 \mathrm{pg} / \mathrm{ml})$

Figure 4. Nigericin reverses the inhibitory effects of IL-22 on NLRP3 inflammasome signaling in HSCs stimulated by TGF- $\beta$. Protein expression levels of NLRP3, caspase 1 and IL-1 $\beta$ in TGF- $\beta$-induced HSCs treated with Nigericin were determined using western blot analysis. ${ }^{* * *} \mathrm{P}<0.001$ vs. control. ${ }^{\# \#} \mathrm{P}<0.01$ and

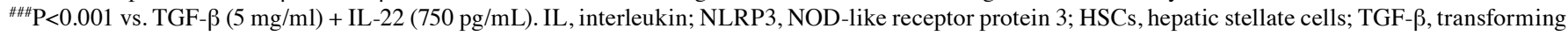
growth factor $\beta$.
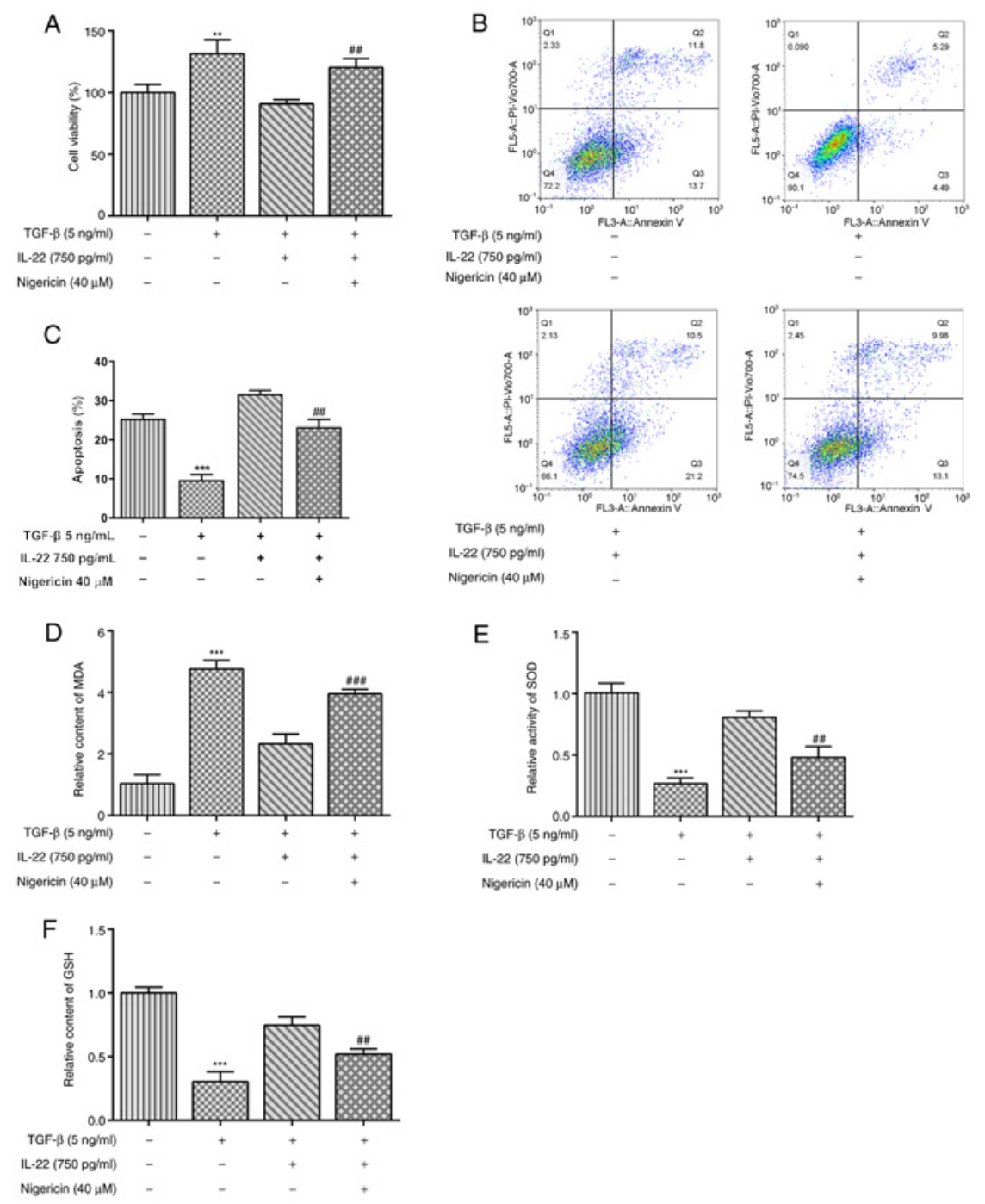

Figure 5. Nigericin reverses the inhibitory effects of IL- 22 on oxidative stress in HSCs stimulated by TGF- $\beta$. (A) Cell viability of TGF- $\beta$-induced HSCs treated with Nigericin was detected using the Cell Counting Kit-8 assay. (B and C) Apoptosis was analyzed using flow cytometry analysis. The relative levels of (D) MDA, (E) SOD and (F) GSH in TGF- $\beta$-induced HSCs treated with Nigericin were evaluated using the corresponding commercial kits. ** $\mathrm{P}<0.01$ and ${ }^{* * * * *} \mathrm{P}<0.001$ vs. control. ${ }^{\# \#} \mathrm{P}<0.01$ and ${ }^{\# \# t} \mathrm{P}<0.001$ vs. TGF- $\beta$ ( $\left.5 \mathrm{ng} / \mathrm{ml}\right)+\mathrm{IL}-22(750 \mathrm{pg} / \mathrm{ml})$. IL-22, interleukin-22; HSCs, hepatic stellate cells; TGF- $\beta$, transforming growth factor $\beta$; MDA, malondialdehyde; SOD, superoxide dismutase; GSH, glutathione.

western blot analysis in TGF- $\beta$-induced HSCs in order to confirm whether IL-22 could alleviate inflammation of TGF- $\beta$-induced HSCs. It was observed that TGF- $\beta$ caused a significant increase in the expression levels of NLRP3, caspase-1 and IL-1 $\beta$, and this effect was reversed by IL-22 (Fig. 3). Therefore, the results suggested that IL-22 inhibited inflammation of TGF- $\beta$-induced HSCs. Treatment of the cells with 500,750 and 1,000 ng/ml IL-22 resulted in a significant decrease of the expression levels of the inflammatory factors. Therefore, IL-22 was used at a concentration of $750 \mathrm{ng} / \mathrm{ml}$ in subsequent experiments. 
A

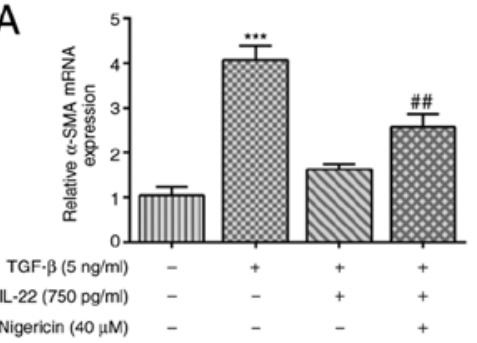

D

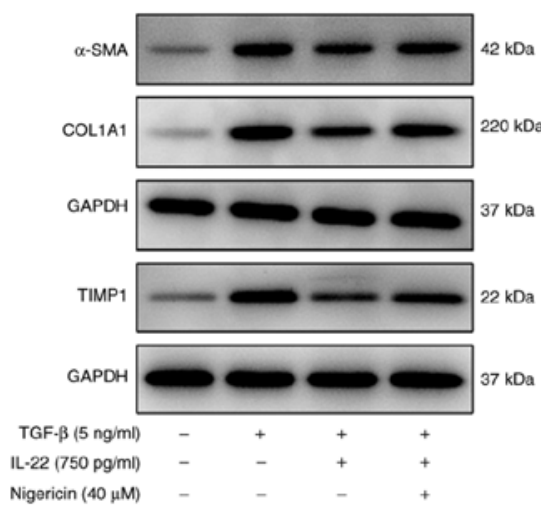

B

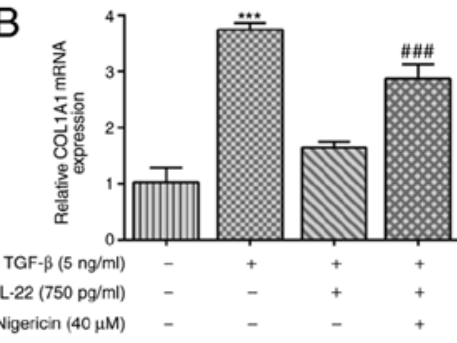

$\alpha$-SMA

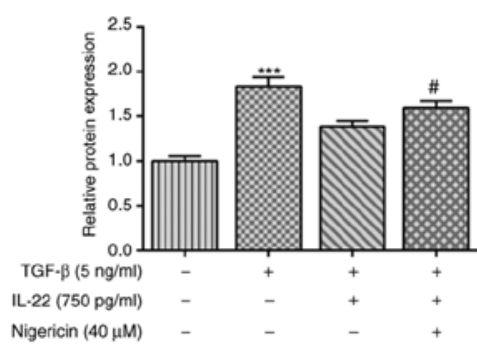

TIMP1

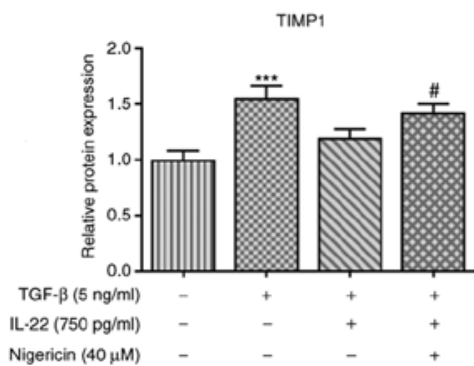

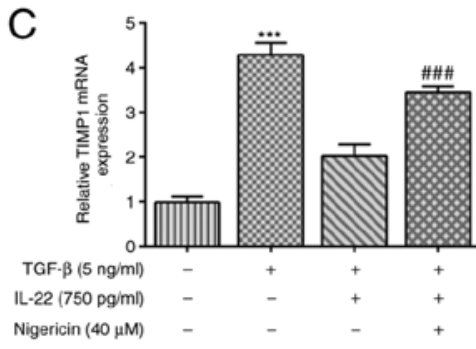

COL1A1

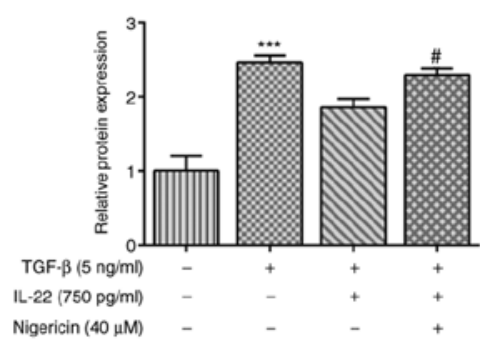

Figure 6. Nigericin restores the inhibitory effects of IL-22 on fibrosis of HSCs stimulated by TGF- $\beta$. The mRNA expression levels of (A) $\alpha$-SMA, (B) COL1A1 and (C) TIMP1 in TGF- $\beta$-induced HSCs treated with Nigericin were determined using reverse transcription-quantitative polymerase chain reaction. (D) Protein expression levels of $\alpha$-SMA, COL1A1 and TIMP1 in TGF- $\beta$-induced HSCs treated with Nigericin were examined using western blot analysis. ${ }^{* * *} \mathrm{P}<0.001$ vs. control. ${ }^{\#} \mathrm{P}<0.05,{ }^{\# \#} \mathrm{P}<0.01$ and ${ }^{\# \# \#} \mathrm{P}<0.001$ vs. TGF- $\beta$ (5 ng/ml) + IL-22 (750 pg/ml). IL-22, interleukin-22; HSCs, hepatic stellate cells; TGF- $\beta$, transforming growth factor $\beta$; $\alpha$-SMA, $\alpha$-smooth muscle actin; COL1A1, collagen type I $\alpha 1$; TIMP1, TIMP metallopeptidase inhibitor 1.

Nigericin reverses the inhibitory effects of IL-22 on oxidative stress and fibrosis in HSCs stimulated by TGF- $\beta$. To further investigate the exact mechanism by which IL-22 exerts its cytoprotective effects, the NLRP3 activator Nigericin was used to treat HSCs. TGF- $\beta$ significantly upregulated the protein expression levels of NLRP3, caspase-1 and IL-1 $\beta$, and this effect was reversed by co-treatment with TGF- $\beta$ and IL-22 (Fig. 4). However, the addition of Nigericin in HSCs co-treated with TGF- $\beta$ and IL-22 significantly increased the expression levels of NLRP3, caspase- 1 and IL-1 $\beta$ compared with HSCs treated with TGF- $\beta$ and IL-22 (Fig. 4). Similarly, CCK- 8 and flow cytometry assays indicated that Nigericin treatment reversed the inhibition of IL-22 on cell viability and apoptosis of TGF- $\beta$-induced HSCs (Fig. 5A-C). In addition, the levels of the oxidative stress indices measured in the present study were significantly reversed following Nigericin treatment in TGF- $\beta$ - and IL-22-induced HSCs compared with TGF- $\beta$ and IL-22 treatment (Fig. 5D-F). Moreover, the results from the RT-qPCR and western blot analyses suggested that the IL-22-induced decreases in the mRNA and protein expression levels of $\alpha$-SMA, COL1A and TIMP1 in TGF- $\beta$-induced HSCs were significantly reversed by Nigericin (Fig. 6A-D). The present results indicated that Nigericin reversed the inhibitory effects of IL-22 on the induction of oxidative stress and fibrosis in HSCs stimulated by TGF- $\beta$.

\section{Discussion}

HSCs are a type of non-parenchymal cells that are important members in the occurrence and development of liver fibrosis and cirrhosis (29). The exposure of HSCs to TGF- $\beta$ transforms their still state into an activated cell form, where HSCs transdifferentiate into proliferative myofibroblasts with pro-fibrogenic transcriptional and secretory properties that are vital for the development of liver fibrosis and collagen deposition $(30,31)$. Therefore, the present study used HSCs activated by TGF- $\beta$ for the simulation of liver fibrosis in vitro.

IL-22 is a factor that protects liver tissues from the development of various chronic diseases, such as nonalcoholic steatohepatitis, liver fibrosis and hepatocellular carcinoma $(15,32)$. IL-22 can promote liver repair and tissue regeneration by stimulating the proliferation and survival of hepatocytes (33). A previous study has suggested that IL-22 exerts inhibitory effects on liver fibrosis and that the attenuation of HSC activation and inhibition of inflammatory factors by IL-22 can restrict liver fibrogenesis (34). Overexpression of IL-22 protects mice from liver injury and liver apoptosis and necrosis stimulated by various factors (35). In the present study, IL-22 inhibited the proliferation of HSCs and the development of liver fibrosis in vitro, which was consistent 
with the aforementioned studies. Immune response and inflammation in the liver are contributors of hepatocyte injury and activation of HSCs (29). The induction of oxidative stress and inflammation activated by TGF- $\beta$ in HSCs was attenuated by IL-22 in the present study.

NLRP3 is an intracellular multi-protein complex, and its activation, which occurs by various types of stimuli, such as endogenous danger signals and environmental irritants, can lead to host defense against microbial infections, activation of caspase-1 and further induction of maturation and secretion of IL-1 $\beta$ and IL-18. This process initiates inflammation $(36,37)$. Inhibition or inactivation of the NLRP3 inflammasome is suggested to enhance lipid metabolism and decrease the levels of inflammation, pyroptosis and the infiltration of immune cells into plaques, thereby alleviating inflammatory responses (38-40). An increased number of studies have reported that the inflammasome and its downstream effectors can trigger liver fibrosis (41-43). The activation of the NLRP3 inflammasome leads to liver inflammation, hepatocyte pyroptosis and liver tissue fibrosis in mice, while pharmacological inhibition of NLRP3 decreases hepatocyte injury and liver inflammation $(42,44)$. Moreover, activation of the NLRP3 signaling pathway triggers the activation of HSCs, which is of great importance for the initiation and development of liver fibrosis $(45,46)$. A previous study focused on the potential drug therapies of liver fibrosis and revealed that the suppression of NLRP3 by oridonin could effectively alleviate this process (47). The selective inhibitor of NLRP3, MCC950, can markedly inhibit liver injury in mice induced by bile duct ligation (41). In the present study, the NLRP3 activator Nigericin was used to confirm the specific role of NLRP3 in liver fibrosis. The addition of Nigericin markedly reversed the inhibitory effect of IL-22 on liver fibrosis of TGF- $\beta$-induced HSCs, which indirectly demonstrated that inhibition of the NLRP3 inflammasome may be an effective and potential therapeutic strategy used in the treatment of liver injury and fibrosis.

In conclusion, the current data indicated that IL-22 may serve an important role in inhibiting liver fibrosis by inactivation of NLRP3 inflammasome signaling, which may provide further insight on the underlying mechanism by which IL-22 exerts protective effects on liver fibrosis. However, in vivo experiments were not performed and the effects of IL-22-knockdown on NLRP3 inflammasome signaling were not investigated in the present study. Therefore, further experiments should be performed in future studies to confirm the present conclusions.

\section{Acknowledgements}

Not applicable.

\section{Funding}

No funding was received.

\section{Availability of data and materials}

The datasets used and/or analyzed during the current study are available from the corresponding author on reasonable request.

\section{Authors' contributions}

ZX and YW searched the literature, designed the experiments and performed the experiments. NL analyzed, interpreted the data and wrote the manuscript. ZX revised the manuscript. ZX and YW confirmed the authenticity of all the raw data. All authors read and approved the final manuscript.

\section{Ethics approval and consent to participate}

Not applicable.

\section{Patient consent for publication}

Not applicable.

\section{Competing interests}

The authors declare that they have no competing interests.

\section{References}

1. Seki E and Brenner DA: Recent advancement of molecular mechanisms of liver fibrosis. J Hepatobiliary Pancreat Sci 22: $512-518,2015$.

2. Matsuda $M$ and Seki E: The liver fibrosis niche: Novel insights into the interplay between fibrosis-composing mesenchymal cells, immune cells, endothelial cells, and extracellular matrix. Food Chem Toxicol 143: 111556, 2020.

3. Zhang CY, Yuan WG, He P, Lei JH and Wang CX: Liver fibrosis and hepatic stellate cells: Etiology, pathological hallmarks and therapeutic targets. World J Gastroenterol 22: 10512-10522, 2016.

4. Friedman SL: Mechanisms of disease: Mechanisms of hepatic fibrosis and therapeutic implications. Nat Clin Pract Gastroenterol Hepatol 1: 98-105, 2004.

5. Wu S, Liu L, Yang S, Kuang G, Yin X, Wang Y, Xu F, Xiong L, Zhang M, Wan J, et al: Paeonol alleviates CCl4-induced liver fibrosis through suppression of hepatic stellate cells activation via inhibiting the TGF- $\beta / \mathrm{Smad} 3$ signaling. Immunopharmacol Immunotoxicol 41: 438-445, 2019.

6. Kumar P, Smith T, Rahman K, Thorn NE and Anania FA: Adiponectin agonist ADP355 attenuates CCl4-induced liver fibrosis in mice. PLoS One 9: e110405, 2014.

7. Schuppan D: Liver fibrosis: Common mechanisms and antifibrotic therapies. Clin Res Hepatol Gastroenterol 39 (Suppl 1): S51-S59, 2015.

8. Kunkl M, Amormino C, Frascolla S, Sambucci M, De Bardi M, Caristi S, Arcieri S, Battistini L and Tuosto L: CD28 autonomous signaling orchestrates IL-22 expression and IL-22-regulated epithelial barrier functions in human T lymphocytes. Front Immunol 11: 590964, 2020.

9. Xie MH, Aggarwal S, Ho WH, Foster J, Zhang Z, Stinson J, Wood WI, Goddard AD and Gurney AL: Interleukin (IL)-22, a novel human cytokine that signals through the interferon receptor-related proteins CRF2-4 and IL-22R. J Biol Chem 275: 31335-31339, 2000.

10. Nagem RA, Colau D, Dumoutier L, Renauld JC, Ogata C and Polikarpov I: Crystal structure of recombinant human interleukin-22. Structure 10: 1051-1062, 2002.

11. Wolk K, Witte E, Witte K, Warszawska K and Sabat R: Biology of interleukin-22. Semin Immunopathol 32: 17-31, 2010.

12. Wang S, Li Y, Fan J, Zhang X, Luan J, Bian Q, Ding T, Wang Y, Wang Z, Song P, et al: Interleukin-22 ameliorated renal injury and fibrosis in diabetic nephropathy through inhibition of NLRP3 inflammasome activation. Cell Death Dis 8: e2937, 2017.

13. Xing WW, Zou MJ, Liu S, Xu T, Gao J, Wang JX and Xu DG: Hepatoprotective effects of IL-22 on fulminant hepatic failure induced by d-galactosamine and lipopolysaccharide in mice. Cytokine 56: 174-179, 2011.

14. Kim DK, Jo A, Lim HS, Kim JY, Eun KM, Oh J, Kim JK, Cho SH and Kim DW: Enhanced type 2 immune reactions by increased IL-22/IL-22Ra1 signaling in chronic rhinosinusitis with nasal polyps. Allergy Asthma Immunol Res 12: 980-993, 2020. 
15. Wu Y, Min J, Ge C, Shu J, Tian D, Yuan Y and Zhou D: Interleukin-22 in liver injury, inflammation and cancer. Int J Biol Sci 16: 2405-2413, 2020.

16. Que R, Shen Y, Ren J, Tao Z, Zhu X and Li Y: Estrogen receptor $\beta$ dependent effects of saikosaponin d on the suppression of oxidative stress induced rat hepatic stellate cell activation. Int J Mol Med 41: 1357-1364, 2018.

17. Pan X, Shao Y, Wang F, Cai Z, Liu S, Xi J, He R, Zhao Y and Zhuang R: Protective effect of apigenin magnesium complex on $\mathrm{H}_{2} \mathrm{O}_{2}$-induced oxidative stress and inflammatory responses in rat hepatic stellate cells. Pharm Biol 58: 553-560, 2020.

18. Novo E, Busletta C, Bonzo LV, Povero D, Paternostro C, Mareschi K, Ferrero I, David E, Bertolani C, Caligiuri A, et al: Intracellular reactive oxygen species are required for directional migration of resident and bone marrow-derived hepatic pro-fibrogenic cells. J Hepatol 54: 964-974, 2011.

19. Li C, Meng M, Guo MZ, Wang MY, Ju AN and Wang CL: The polysaccharides from Grifola frondosa attenuate CCl4-induced hepatic fibrosis in rats via the TGF-beta/Smad signaling pathway. RSC Advances 9: 33684-33692, 2019.

20. Ting JP, Lovering RC, Alnemri ES, Bertin J, Boss JM, Davis BK, Flavell RA, Girardin SE, Godzik A, Harton JA, et al: The NLR gene family: A standard nomenclature. Immunity 28: 285-287, 2008.

21. Wu X, Dong L, Lin X and Li J: Relevance of the NLRP3 inflammasome in the pathogenesis of chronic liver disease. Front Immunol 8: 1728, 2017.

22. Feng D, Mukhopadhyay P, Qiu J and Wang H: Inflammation in liver diseases. Mediators Inflamm 2018: 3927134, 2018.

23. Wang S, Li Y, Fan J, Zhang X, Luan J, Bian Q, Ding T, Wang Y, Wang $\mathrm{Z}$, Song $\mathrm{P}$, et al: Interleukin-22 ameliorated renal injury and fibrosis in diabetic nephropathy through inhibition of NLRP3 inflammasome activation. Cell Death Dis 8: e2937, 2017.

24. Wang S, Fan J, Mei X, Luan J, Li Y, Zhang X, Chen W, Wang Y, Meng $G$ and $J u$ D: Interleukin-22 attenuated renal tubular injury in aristolochic acid nephropathy via suppressing activation of NLRP3 inflammasome. Front Immunol 10: 2277, 2019.

25. Chen E, Cen Y, Lu D, Luo W and Jiang H: IL-22 inactivates hepatic stellate cells via downregulation of the TGF- $\beta 1 /$ Notch signaling pathway. Mol Med Rep 17: 5449-5453, 2018.

26. Mu M, Zuo S, Wu RM, Deng KS, Lu S, Zhu JJ, Zou GL, Yang J, Cheng ML and Zhao XK: Ferulic acid attenuates liver fibrosis and hepatic stellate cell activation via inhibition of TGF- $\beta / \mathrm{Smad}$ signaling pathway. Drug Des Devel Ther 12: 4107-4115, 2018.

27. Martine P, Chevriaux A, Derangère V, Apetoh L, Garrido C, Ghiringhelli $\mathrm{F}$ and Rébé C: HSP70 is a negative regulator of NLRP3 inflammasome activation. Cell Death Dis 10: 256, 2019.

28. Livak KJ and Schmittgen TD: Analysis of relative gene expression data using real-time quantitative PCR and the 2(-Delta Delta C(T)) Method. Methods 25: 402-408, 2001.

29. Aslamazova EB, Stroganova EV and Dzhinanian VL: Pathogenesis of liver cirrhosis. Ter Arkh 47: 30-34, 1975, (In Russian).

30. Lakner AM, Steuerwald NM, Walling TL, Ghosh S, Li T, McKillop IH, Russo MW, Bonkovsky HL and Schrum LW: Inhibitory effects of microRNA $19 \mathrm{~b}$ in hepatic stellate cell-mediated fibrogenesis. Hepatology 56: 300-310, 2012.

31. Friedman SL: Hepatic stellate cells: Protean, multifunctional, and enigmatic cells of the liver. Physiol Rev 88: 125-172, 2008.

32. Hwang S, He Y, Xiang X, Seo W, Kim SJ, Ma J, Ren T, Park SH, Zhou Z, Feng D, et al: Interleukin-22 ameliorates neutrophil-driven nonalcoholic steatohepatitis through multiple targets. Hepatology 72: 412-429, 2020.

33. Zenewicz LA, Yancopoulos GD, Valenzuela DM, Murphy AJ, Karow M and Flavell RA: Interleukin-22 but not interleukin-17 provides protection to hepatocytes during acute liver inflammation. Immunity 27: 647-659, 2007.
34. Lu DH, Guo XY, Qin SY, Luo W, Huang XL, Chen M, Wang JX, Ma SJ, Yang XW and Jiang HX: Interleukin-22 ameliorates liver fibrogenesis by attenuating hepatic stellate cell activation and downregulating the levels of inflammatory cytokines. World J Gastroenterol 21: 1531-1545, 2015.

35. Xu K, Sun J, Chen S, Li Y, Peng X, Li M and Li Y: Hydrodynamic delivery of IL-38 gene alleviates obesity-induced inflammation and insulin resistance. Biochem Biophys Res Commun 508: 198-202, 2019

36. Vandanmagsar B, Youm YH, Ravussin A, Galgani JE, Stadler K, Mynatt RL, Ravussin E, Stephens JM and Dixit VD: The NLRP3 inflammasome instigates obesity-induced inflammation and insulin resistance. Nat Med 17: 179-188, 2011.

37. Swanson KV, Deng M and Ting JPY: The NLRP3 inflammasome: Molecular activation and regulation to therapeutics. Nat Rev Immunol 19: 477-489, 2019.

38. Duewell P, Kono H, Rayner KJ, Sirois CM, Vladimer G, Bauernfeind FG, Abela GS, Franchi L, Nuñez G, Schnurr M, et al: NLRP3 inflammasomes are required for atherogenesis and activated by cholesterol crystals. Nature 464: 1357-1361, 2010.

39. Wang R, Wang Y, Mu N, Lou X, Li W, Chen Y, Fan D and Tan H: Activation of NLRP3 inflammasomes contributes to hyperhomocysteinemia-aggravated inflammation and atherosclerosis in apoE-deficient mice. Lab Invest 97: 922-934, 2017.

40. Abderrazak A, Couchie D, Mahmood DF, Elhage R, Vindis C, Laffargue M, Matéo V, Büchele B, Ayala MR,El Gaafary M, et al: Anti-inflammatory and antiatherogenic effects of the NLRP3 inflammasome inhibitor arglabin in ApoE2.Ki mice fed a high-fat diet. Circulation 131: 1061-1070, 2015.

41. Qu J, Yuan Z, Wang G, Wang X and Li K: The selective NLRP3 inflammasome inhibitor MCC950 alleviates cholestatic liver injury and fibrosis in mice. Int Immunopharmacol 70: 147-155, 2019.

42. Wree A, Eguchi A, McGeough MD, Pena CA, Johnson CD, Canbay A, Hoffman HM and Feldstein AE: NLRP3 inflammasome activation results in hepatocyte pyroptosis, liver inflammation, and fibrosis in mice. Hepatology 59: 898-910, 2014.

43. Wu X, Zhang F, Xiong X, Lu C, Lian N, Lu Y and Zheng S: Tetramethylpyrazine reduces inflammation in liver fibrosis and inhibits inflammatory cytokine expression in hepatic stellate cells by modulating NLRP3 inflammasome pathway. IUBMB Life 67: 312-321, 2015

44. Mridha AR, Wree A, Robertson AAB, Yeh MM, Johnson CD, Van Rooyen DM, Haczeyni F, Teoh NC, Savard C, Ioannou GN, et al: NLRP3 inflammasome blockade reduces liver inflammation and fibrosis in experimental NASH in mice. J Hepatol 66: 1037-1046, 2017.

45. Watanabe A, Sohail MA, Gomes DA, Hashmi A, Nagata J, Sutterwala FS, Mahmood S, Jhandier MN, Shi Y, Flavell RA, et al: Inflammasome-mediated regulation of hepatic stellate cells. Am J Physiol Gastrointest Liver Physiol 296: G1248-G1257, 2009.

46. Inzaugarat ME, Johnson CD, Holtmann TM, McGeough MD, Trautwein C, Papouchado BG, Schwabe R, Hoffman HM, Wree A and Feldstein AE: NLR family pyrin domain-containing 3 inflammasome activation in hepatic stellate cells induces liver fibrosis in mice. Hepatology 69: 845-859, 2019.

47. Liu D, Qin H, Yang B, Du B and Yun X: Oridonin ameliorates carbon tetrachloride-induced liver fibrosis in mice through inhibition of the NLRP3 inflammasome. Drug Dev Res 81: 526-533, 2020 .

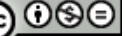

This work is licensed under a Creative Commons Attribution-NonCommercial-NoDerivatives 4.0 International (CC BY-NC-ND 4.0) License. 